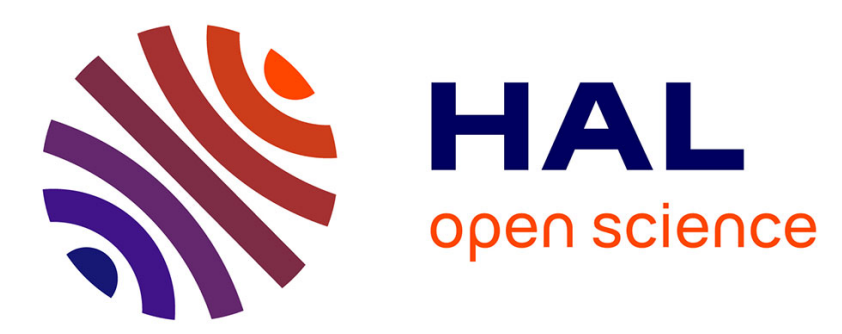

\title{
Electro-mechanical Resonant Ice Protection Systems: Energetic and Power Considerations
}

Marc Budinger, Valérie Pommier-Budinger, Aurelien Reysset, Valerian Palanque

\section{- To cite this version:}

Marc Budinger, Valérie Pommier-Budinger, Aurelien Reysset, Valerian Palanque. Electro-mechanical Resonant Ice Protection Systems: Energetic and Power Considerations. AIAA Journal, 2021, 59 (7), pp.2590-2602. 10.2514/1.J060008 . hal-03342185

\section{HAL Id: hal-03342185 \\ https://hal.science/hal-03342185}

Submitted on 13 Sep 2021

HAL is a multi-disciplinary open access archive for the deposit and dissemination of scientific research documents, whether they are published or not. The documents may come from teaching and research institutions in France or abroad, or from public or private research centers.
L'archive ouverte pluridisciplinaire HAL, est destinée au dépôt et à la diffusion de documents scientifiques de niveau recherche, publiés ou non, émanant des établissements d'enseignement et de recherche français ou étrangers, des laboratoires publics ou privés. 


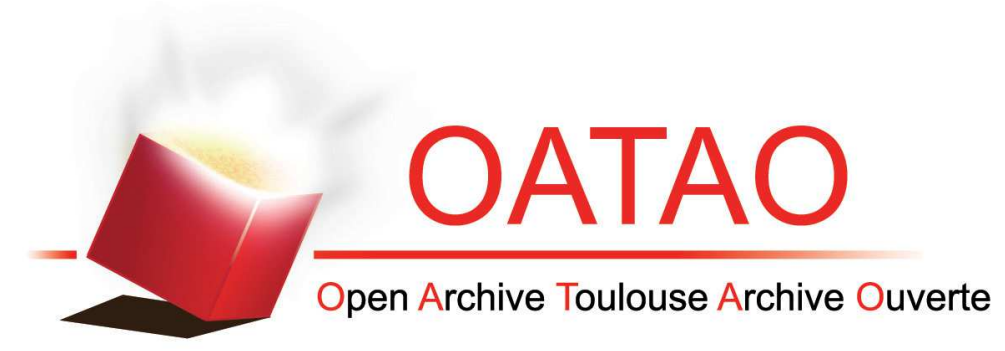

\section{Open Archive Toulouse Archive Ouverte (OATAO)}

OATAO is an open access repository that collects the work of some Toulouse researchers and makes it freely available over the web where possible.

This is an author's version published in: https://oatao.univ-toulouse.fr/28276

Official URL : https://doi.org/10.2514/1.J060008

\section{To cite this version :}

Budinger, Marc and Pommier-Budinger, Valérie and Reysset, Aurelien and Palanque, Valerian Electro-mechanical Resonant Ice Protection Systems: Energetic and Power Considerations. (2021) AIAA Journal, 59 (7). ISSN 0001-1452

Any correspondence concerning this service should be sent to the repository administrator: tech-oatao@listes-diff.inp-toulouse.fr 


\title{
Electromechanical Resonant Ice Protection Systems: Energetic and Power Considerations
}

\author{
Marc Budinger* \\ University of Toulouse, 31400 Toulouse, France \\ and \\ Valérie Pommier-Budinger, \pm Aurélien Reysset, \pm and Valerian Palanque $\stackrel{\S}{\S}$ \\ University of Toulouse, 31055 Toulouse, France \\ https://doi.org/10.2514/1.J060008
}

\begin{abstract}
This paper focuses on resonant ice protection systems and proposes key performance indicators to analyze the performances of such systems with respect to levels of energy, force, and power required for de-icing. The principle of these systems is to apply vibrations or ultrasonic waves onto the structure that create high-level stresses greater than those required to crack and delaminate to remove the ice accumulated on the structure. The computation of the indicators requires two values: the ice adhesion strength and the critical strain energy release rate. Computations are performed assuming three stages of a de-icing mechanism: first, an initiation of cohesive fractures by tensile stress at the top surface of the ice layer; second, a propagation of cohesive fractures within the ice; and, third, a propagation of adhesive fractures at the ice/substrate interface starting from the base of the cohesive fractures previously created. The proposed key performance indicators provide guidance on the use of flexural and extensional modes in resonant ice protection systems and on the frequency range to favor when looking at fractures initiation and propagation. Calculations based on the key performance indicators show a potential power reduction by 10 with resonant electromechanical de-icing systems compared to electrothermal systems.
\end{abstract}

\section{Nomenclature}

$=$ depth of plate, $\mathrm{m}$

$b$

$F$

$f_{r}$

G

$G_{\mathrm{adh}_{X \%}}$

$G_{c}$

$G_{c_{\text {adh }}}$

$G_{c_{\text {coh }}}$

$G_{\operatorname{coh}_{X \%}}$

$k$

KPI

$L_{f}$

$L_{f, \mathrm{adh}_{X \%}}$

$L_{f, \operatorname{coh}_{X \%}}$

$P_{\text {mech }}$

$Q_{m}$

$t$

$u_{i}$

$x_{\max }$

$\dot{x}_{\max }$

$\sigma$

$\sigma_{\text {shear }}$

$\sigma_{\text {tensile }}$

$=$ force, $\mathrm{N}$

$=$ resonance frequency, $\mathrm{Hz}$

$=$ stiffness, $\mathrm{N} \cdot \mathrm{m}^{-1}$

$=$ length of fracture, $\mathrm{m}$

= mechanical power, $\mathrm{W}$

$=$ quality factor

= ice thickness, $\mathrm{m}$

$=$ stored elastic energy, $\mathrm{J}$

$=$ maximal displacement, $\mathrm{m}$

$=$ maximal speed, $\mathrm{m}$

$=$ stress, $\mathrm{Pa}$

$=$ shear strength, $\mathrm{Pa}$

$=$ tensile strength, $\mathrm{Pa}$
$=$ strain energy release rate $\mathrm{J} \cdot \mathrm{m}^{-2}$

$=$ adhesive strain energy release rate, $\mathrm{J} \cdot \mathrm{m}^{-2}$

$=$ critical strain energy release rate, $\mathrm{J} \cdot \mathrm{m}^{-2}$

$=$ critical adhesive strain energy release rate, $\mathrm{J} \cdot \mathrm{m}^{-2}$

$=$ critical cohesive strain energy release rate, $\mathrm{J} \cdot \mathrm{m}^{-2}$

$=$ cohesive strain energy release rate, $\mathrm{J} \cdot \mathrm{m}^{-2}$

$=$ key performance indicators

$=$ length of adhesive fracture, $\mathrm{m}$

$=$ length of cohesive fracture, $\mathrm{m}$ $\omega$

$=$ resonance angular frequency, $\mathrm{rad} \cdot \mathrm{s}^{-1}$

\section{Introduction}

$\mathbf{I}$ CING occurs when an aircraft flies through clouds in which supercooled droplets are suspended in an atmosphere with an ambient air temperature below the freezing point. The droplets impinge on the aircraft surfaces and freeze, leading to ice accretion. The resulting change in the aircraft geometry can alter wing aerodynamic characteristics (loss of lift and increase in drag) or even damage the engine by ice ingestion. Regarding electrical de-icing systems, electrothermal and electroimpulse technologies are already implemented on aircraft, but studies are currently in progress to propose new solutions that consume less energy or have less bulky power supplies. Some authors have tried using ultrasonic waves. This article focuses on resonant de-icing systems, mainly based on piezoelectric systems, which are a subject of growing interest. The principle of these systems is to apply vibrations onto the structure that create high-level stresses greater than those required to bring about cracks and delamination to remove the ice accumulated on the structure. The advantage of resonant de-icing systems is that they naturally amplify the displacements at resonance frequencies, thus requiring smaller effort than static deformation or impact. The interest of resonant de-icing systems justifies the numerous studies on this topic. Results have been obtained for a large variety of frequency ranges.

Some works on resonant de-icing systems are based on the use of ultrasonic shear waves at very high frequency (around $1 \mathrm{MHz}$ ). Ramanathan et al. [1] performed experiments with piezoelectric patches bonded to a plate. The core of the concept is to use the stress distribution associated with waves propagating through the structure to detach the ice. However, in this experience, the de-icing was obtained by melting the ice at the interface. Shi and Jia [2] investigated the use of shear wave de-icing driven by a macrofiber piezoelectric composite actuator on a composite plate. The actuator was driven by multimodal excitation through three broadband sweeps between $100 \mathrm{kHz}$ and $1 \mathrm{MHz}$ for de-icing at relatively small excitation amplitude. De-icing was obtained, but only after $240 \mathrm{~s}$. It is questionable whether de-icing was not due to thermal effects.

On the other hand, some works explore lower frequencies. Venna and Lin [3-5], Venna et al. [6] used piezoelectric ceramics bonded to plates and to the inner flat surface of a leading edge structure to excite

\footnotetext{
*Associate Professor, ICA/INSA Toulouse, Mechanical Engineering Department, INSA, ISAE-SUPAERO, MINES ALBI, UPS, CNRS, 3 Rue Caroline Aigle.

'Professor, ISAE-Supaero Toulouse/Department of Aerospace Vehicles Design and Control, 10 Avenue Edouard Belin.

${ }^{\ddagger}$ Research Engineer, ISAE-Supaero Toulouse/Department of Aerospace Vehicles Design and Control, 10 Avenue Edouard Belin.

${ }^{\S}$ Ph.D. Student; currently ISAE-Supaero Toulouse/Department of Aerospace Vehicles Design and Control and ONERA/DMPE, Avenue Edouard Belin.
} 
low frequency modes (below $1000 \mathrm{~Hz}$ ). Struggl et al. [7] used the same frequency range with piezoelectric ceramics bonded to a plate and to a leading edge structure to excite low frequency modes (below $500 \mathrm{~Hz}$ ). Partial de-icing was obtained during these experiments.

Palacios et al. initiated many studies on de-icing systems at frequency around a few tens of kilohertz on plates [8] and on leading edges [9]. At such frequencies, the delamination of the ice was instantaneous but quite energy intensive compared to low frequency. In [9], they started using finite element models to predict the ultrasonic ice shedding transverse shear stresses. Overmeyer et al. pursued this approach in [10] to design a piezoelectric de-icing system able to promote shedding of ice layers ranging from 1.4 to $7.1 \mathrm{~mm}$ in thickness while varying icing conditions, and in [11], DiPlacido et al. studied the effect of tone burst excitation: enhanced de-icing ability is observed when employing multifrequency bursts.

Daniliuk et al. [12] explored different Langevin piezoelectric transducers to de-ice plates. In the best case, partial de-icing was obtained. Experiments showed many cohesive fractures or delamination, but not on the whole surface of the plates.

Concerning the question of the de-icing efficiency, it is interesting to read the work of Endres et al. [13], who showed that the de-icing performance depends on the ice layer thickness and the environmental temperature. In [14], Villeneuve et al. worked on the actuator positioning and activation strategies.

One question to advance research on resonant electromechanical de-icing systems is to find the appropriate substrates (material, thickness, and boundary conditions) and the icing conditions that lead to complete ice removal on surfaces prone to ice accretion.

To answer this question, our approach combines analytical or numerical analysis with experimental results. In the work of Budinger et al. [15], different architectures of de-icing systems based on piezoelectric actuators are compared, and the frequency ranges and types of modes that are the most favorable for de-icing are discussed. These tests were performed with a Langevin piezoelectric transducer. As the de-icing mechanism of electromechanical ice protection systems is based on fracture initiation and propagation, the initiation of ice fractures by piezoelectric actuator systems was first studied in [16]. However, the initiation of fractures is not a sufficient condition to obtain complete ice removal. Several authors started studying ice fracture propagation in ice protection systems. In [17], Bennani paved the way to the discussions for modeling the mechanical behavior of atmospheric ice with fractures. His approach is based on the variational phase-field fracture model. One advantage of this method is that it does not assume the location of the fractures. The proposed code estimates the locations where fractures are initiated and allows for studying their propagation. This code was extended by Marboeuf et al. [18], who studied the choice of input parameters in the model. Sommerwerk and Horst [19] used the cohesive zone model (CZM) to study the fracture propagation inside the ice layer [19]. Then, in [20], the model was combined with shear stress criterion to extend the study to the determination of ice detachment from the structure. Bailey [21] and Drury [22] also chose the CZM method to study the delamination of rotor blades as the site of crack nucleation was not known. In [23], Budinger et al. proposed an approach based on the classical Griffith energy balance and finite element modal analyses. This approach requires assumptions on fracture pattern but does not require the traction-separation laws requested by the CZM method, which can be useful in a preliminary design approach.

This paper further analyzes ice fracture mechanisms and establishes key performance indicators needed to find the best resonance modes, in other words, the most efficient for removing ice with minimal energy, power, and force. These indicators are set up so as to be independent of the vibratory amplitude and of certain highly variable parameters of the ice and of the ice/substrate interface which play a role in the initiation and propagation of fractures. They thus make it possible to capture in a quantitative and condensed manner the de-icing potential of a given geometry of substrate covered with a type of ice according to different resonant modes and frequencies.

The paper is organized in three main sections. Section II is dedicated to the computational method implemented to analyze the propagation of cohesive and adhesive fractures. This method has been established based on the analysis of de-icing mechanisms observed during experiments performed with freezer ice. Then, in Sec. III, key performance indicators are proposed to analyze the efficiency of resonant de-icing systems while looking at the energy, power, and force requirements. At last, Sec. IV proposes the computation and analysis of the key performance indicators on a case study and provides guidance on the use of flexural and extensional modes in resonant ice protection systems and on the frequency range to favor fractures initiation and propagation.

\section{Computational Method for Fracture Propagation Analysis}

\section{A. De-icing Mechanisms}

The de-icing mechanism of electromechanical ice protection systems is based on the initiation and propagation of cohesive and adhesive fractures in the ice. Based on fracture mechanics theory, two types of fractures can be differentiated: cohesive fractures within the ice itself and adhesive fractures that occur in the area of adhesion between the ice and the substrate (Fig. 1). The propagation of fractures after their initiation has been studied in [23], and two deicing mechanisms have been stated for resonant ice protection systems (Table 1 ).

The first mechanism corresponds to the initiation of cohesive fractures caused by tensile stresses, the propagation of cohesive fractures, and then potentially the propagation of adhesive fractures. More precisely, it can be described as follows:

1) First, cohesive fractures are initiated due to tensile stress.

2) Second, just after the initiation of cohesive fractures at the top surface of the ice layer, the cohesive fractures propagate through the ice.

3) Third, adhesive fractures propagate at the ice/substrate interface, starting from the base of the cohesive fractures previously created.

The second mechanism corresponds to the initiation of fractures due to shear stress at the ice/substrate interface and to the propagation of adhesive fractures.

Some authors also experienced cohesive fractures close to the ice and substrate interface. This fracture mechanism can be misinterpreted as adhesive fracture. Nevertheless, it will not be investigated in this paper.

In [23], these two mechanisms have been studied in the case of flexural and extensional modes. It has been shown that, for flexural modes, the first mechanism with initiation of fractures due to tensile stresses followed by cohesive and adhesive fractures is the most probable. This mechanism was also observed during the experiments presented in [24]. The second mechanism has been reported for

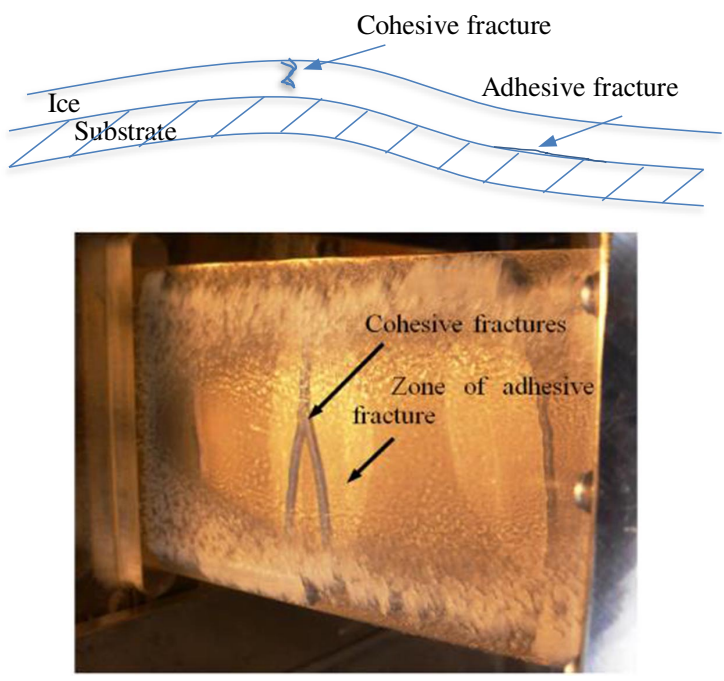

Fig. 1 Cohesive and adhesive fractures. 
Table 1 Fracture propagation mechanisms for resonant de-icing systems

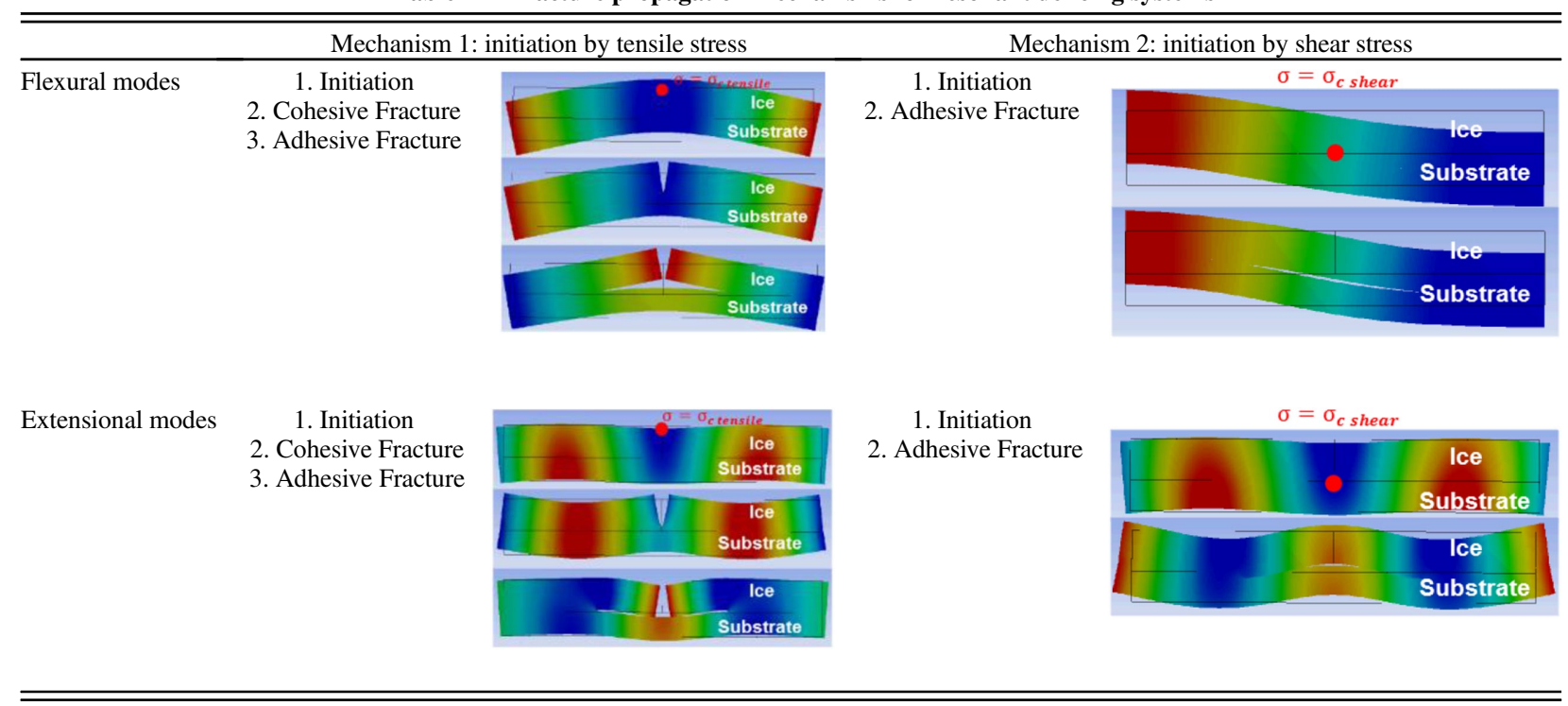

extensional modes at high frequencies (tens of kilohertz) by Palacios et al. in $[\underline{8}, 9]$.

\section{B. Observation and Effects of Flexural Modes on De-Icing of Freezer Ice}

First, experimental tests were conducted to verify the chronology of cohesive and adhesive fractures assumed in Sec. II.A for flexural modes. These tests also aimed at observing the influence of the boundary conditions and ice thickness.

The specimens for de-icing tests consist of plates on which a piezoelectric actuator is bonded on the side opposite to the surface where ice accretion takes place. The piezoelectric actuator is driven through a $300 \mathrm{~W}$ power amplifier (maximum output $100 \mathrm{~V}$ ), connected to a transformer for cases requiring higher voltages. De-icing tests with different boundary conditions (free and clamped) and different ice layer thicknesses were performed. While visual observation of cohesive fractures in ice is not a problem, it is more difficult to observe adhesive fractures. The zone at the ice/substrate interface where adhesive fractures occur can be visible by a whitish appearance characteristic of the ice detachment and of the infiltration of air between the ice and the substrate (Fig. 1).

Test specimens were titanium alloy plates of size $130 \times 70 \times 1 \mathrm{~mm}^{3}$ with two piezoelectric ceramics (PIC 151 material from Physik Instrumente, size $50 \times 25 \times 0.5 \mathrm{~mm}^{3}$ ) bonded to them, one used as a sensor and the other as an actuator. Piezoelectric ceramics were bonded to the clamped sides of the plate for tests in clamped conditions and in the middle of the plate for tests in free conditions (Fig. 2). The ceramics were placed next to antinodes to get a high electromechanical coupling for these specific modes [25]. Another option would have been to place the ceramics in the middle of the sample where the stresses are also important. The electromechanical coupling between the two configurations is of the same order of magnitude, and the two options can be envisaged for carrying out tests. The influence of the ice layer thickness was studied by performing tests with ice layers of different thicknesses: 1, 2, or $3 \mathrm{~mm}$.

The ice was obtained in a freezer by spraying demineralized water on the substrate. The substrate was placed in $\mathrm{a}-20^{\circ} \mathrm{C}$ freezer at least $12 \mathrm{~h}$ before starting the accretion and the volume of demineralized water required to obtain 1-, 2-, or 3-mm-thick ice layers was cooled down to $0^{\circ} \mathrm{C}$. Every $20 \mathrm{~s}, 3 \mathrm{~g}$ of precooled water were pulverized, forming a homogenous ice bloc all over the substrate. The operation is repeated until getting the required ice layer.

De-icing tests were first conducted for flexural modes (modes 1 and 12 of the plate) in free conditions. One test corresponds to measurements in a frequency range in the vicinity of the frequency $f_{r}$ that needed to be excited. For each test, the voltage applied to the actuator was set as follows:

1) The frequency was swept on a narrow bandwidth, $\left[f_{r}-x \mathrm{~Hz}\right.$, $\left.f_{r}+x \mathrm{~Hz}\right], x$ being selected for each test such that only one resonance mode is excited. The frequency was swept in the frequency range with a step of $1 \mathrm{~Hz}$ for the tests in low frequencies and $5 \mathrm{~Hz}$ for the tests in high frequencies. Each step lasted $0.1 \mathrm{~s}$ approximately. This value ensures that the steady state is reached.

2) The amplitude was increased by step of $10 \mathrm{~V}$ from 10 to $30 \mathrm{~V}$ and then by step of $2 \mathrm{~V}$ until the first fractures occurred.

Results are given in Table 2 for both modes, but de-icing test results are only shown for mode 1 .

For the 1-mm-thick configuration, test results are shown at $54 \mathrm{~V}$, which is the voltage where the fractures appeared (consequently considered as the voltage for fracture initiation). In Fig. 3a, only a cohesive fracture is observed in the middle of the plate (that corresponds to the line of antinodes where the maximum stress occurs for the first flexural mode), and no adhesive fracture occurs. This cohesive fracture corresponds to the first two stages of mechanism 1 .

For the 2-mm-thick configuration, Fig. $3 \mathrm{~b}$ shows the de-icing results for $46 \mathrm{~V}$ (voltage for fracture initiation). A cohesive fracture is observed in the middle of the plate as well as a small opaque zone

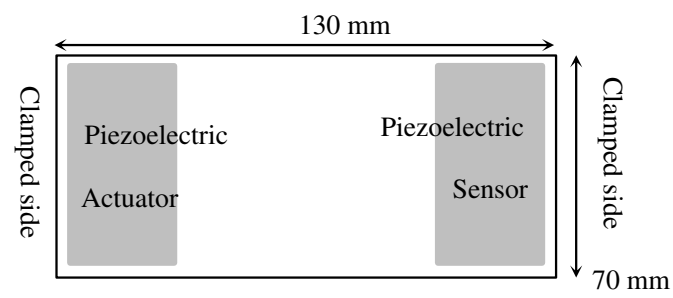

a)

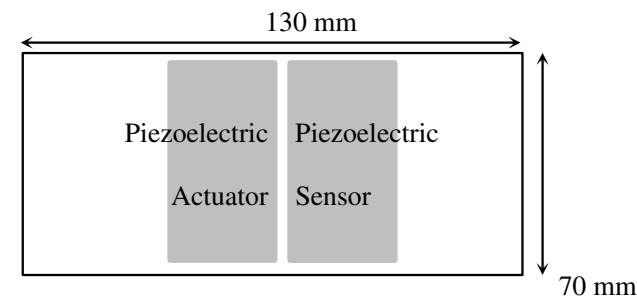

b)

Fig. 2 Test specimen for a) clamped conditions and b) free conditions. 
Table 2 De-icing mechanisms for flexural resonant systems

\begin{tabular}{lcccc}
\hline \hline Mode number and type & Frequency, $\mathrm{Hz}$ & Ice layer thickness, $\mathrm{mm}$ & Type of fracture & Voltage amplitude for fracture initiation, $\mathrm{V}$ \\
\hline 1 & 478 & 1 & Cohesive & 54 \\
Flexural & 647 & 2 & Cohesive \& adhesive & 46 \\
& 855 & 3 & Cohesive \& adhesive & 54 \\
\hline 12 & 3317 & 1 & Cohesive & 40 \\
Flexural & 5225 & 2 & Cohesive & 50 \\
& 7056 & 3 & Cohesive & 40 \\
\hline \hline
\end{tabular}

(5.5 mm wide) that corresponds to adhesive fracture. When an adhesive fracture is observed after a cohesive fracture, it is assumed that the crack is through the whole thickness. In this test, the three stages of mechanism 1 were thus present. With a 3 -mm-thick ice layer, de-icing initiation occurred for a higher voltage of $54 \mathrm{~V}$. Both a cohesive fracture in the middle of the plate and an adhesive fracture larger $(7.5 \mathrm{~mm}$ wide) than with the $2-\mathrm{mm}$-thick configuration are observed (Fig. 3c). These fractures correspond to the three steps of mechanism 1.

Finally, concerning the boundary conditions, for the test specimen with the clamped boundary conditions, it was not possible to generate fractures within the limits of the power supply. It shows that clamped boundary conditions require more power for de-icing than free boundary conditions. In this study [24,26], fractures were obtained in clamped conditions with high voltage (from 300 to $600 \mathrm{Vpp}$ (Peakto-peak voltage)) confirming the much higher voltage requirements of clamped conditions.

\section{Observation and Effects of Extensional Modes on De-Icing of Freezer Ice}

This section aims at observing and validating the de-icing mechanism for extensional modes. The specimen for de-icing tests is again a titanium alloy plate of size $130 \times 70 \times 1 \mathrm{~mm}^{3}$ (Fig. 4a). The actuation system of piezoelectric ceramics has been designed to favor a pure extensional mode at $15 \mathrm{kHz}$ [first mode of extension in free condition (Fig. 4b)]. Ceramics were added (Fig. 4a) to the previous design in order to get a more constant substrate thickness and reduce flexural undesired effects. Even though the ceramic surface has been increased, only the two largest ceramics were used as actuators. Therefore, the actuating area remained equivalent to previous specimens: two bonded ceramics (PIC 151, size $50 \times 25 \times 0.5 \mathrm{~mm}^{3}$ ). Finite elements modeling results indicate that a 3 -mm-thick ice layer would minimize the flexural effects. Tests were therefore performed with such a layer of ice, which was deposited in the same way as for the previous tests.

The extensional mode was excited simultaneously by the two main ceramics with a voltage of $150 \mathrm{~V}$. The test was carried out several times, and this voltage has been identified in the first tests as the maximum voltage that can be delivered by the power supply (consumed current of $2 \mathrm{~A}$ and maximum power of $300 \mathrm{~W}$ ). This voltage is greater than the estimated voltage to initiate cohesive fractures in the ice (a minimum voltage of 93 Von both actuators was computed). For the test presented in this paper, apart from a few low voltage sweeps (10 to $20 \mathrm{kHz}$ ) to identify the mode frequency, the voltage was directly set to this maximum value of the power supply to reduce the overall actuation time and therefore avoid heating effects. The whole frequency range around the resonance frequency $(700 \mathrm{~Hz})$ was swept under $10 \mathrm{~s}$ with $10 \mathrm{~Hz}$ steps. For each step, the frequency was held for over 900 periods, ensuring that, at the resonant frequency, the structure will have the time to reach its steady state conditions as suggested in [23]. As expected, because the excitation voltage is much greater than the computed minimum voltage for fracture initiation ( $150 \mathrm{v}$ ersus $93 \mathrm{~V})$, both cohesive and adhesive fractures were observed instantaneously (Fig. 5). The whitish area is the area

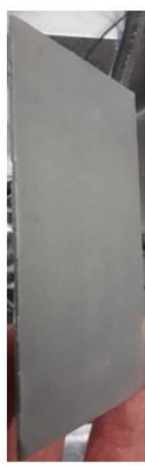

a)

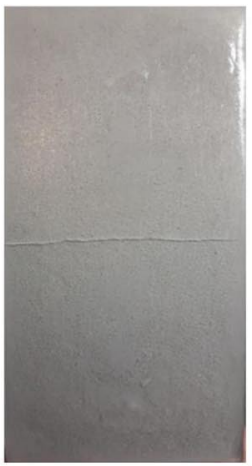

(b)

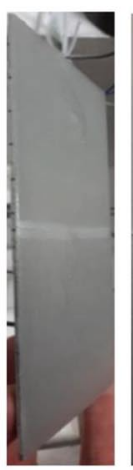

b)

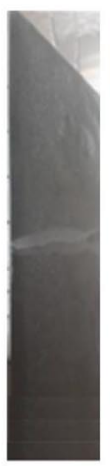

c)

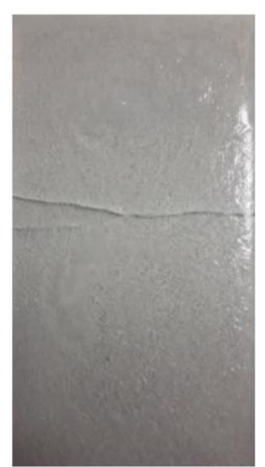

Fig. 3 Test result in freezer for mode 1 and ice layer of thickness a) 1, b) 2, and c) $3 \mathrm{~mm}$.

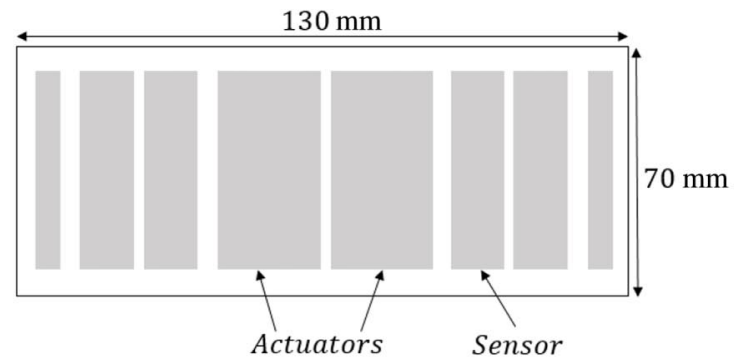

a)

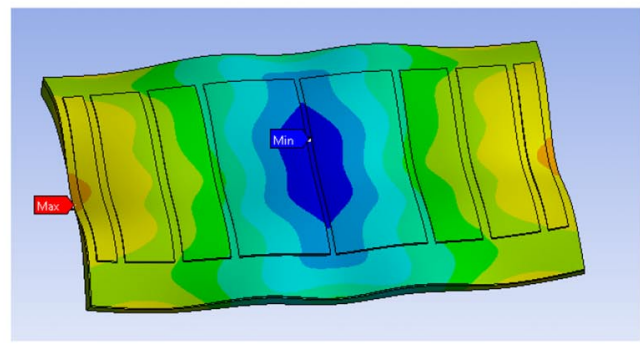

b)

Fig. 4 Test specimen for extensional mode: a) piezoelectric ceramics implementation and b) first extensional mode. 


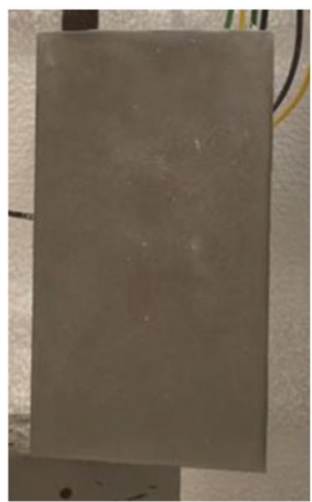

a)

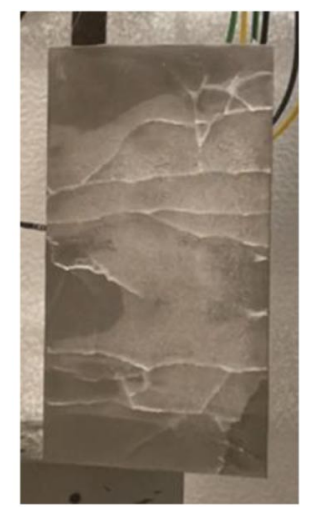

b)

Fig. 5 Test results for $15.3 \mathrm{kHz}$ extensional mode and 3-mm-thick ice layer: a) before and b) after actuation.

where the bond between ice and substrate is broken. Contrary to flexural modes, cohesive fractures do not follow a specific path. Fractures are perpendicular to the displacement, but there are no indications on the location of the initiation of the cracks. Most cohesive fractures are followed by adhesive fractures. Adhesive fractures seem to propagate from the center of the plate toward both ends. After the first sweep, a second sweep of equivalent intensity was realized, but there was no further propagation. The debonded area is measured and estimated to $78 \%$ of the total icing area. The propagation seems to have reached a limit for this extension mode. However, another sweep at lower frequency to excite the first flexural modes between 1300 and $2800 \mathrm{~Hz}$ made it possible to obtain complete removal of the ice.

\section{Computational Method}

The mechanism of ice cracking through the thickness of the ice occurs when the tensile stress in the ice exceeds the tensile strength of the ice accumulated on the surface. The mechanism of ice delamination occurs when the transverse shear stress at the surface/ice interface exceeds the adhesive shear strength of the ice.

The computational method to study the propagation of fractures is derived from the method proposed in [23] based on the classical Griffith energy balance approach. The propagation velocity of the crack is assumed to be sufficiently important to neglect the phenomena of inertia and relaxation of the plate. It is also assumed that the fracture propagation direction is known and that a certain amount of energy is absorbed by the structure during the formation of an area of fracture surface. When the fracture propagates, a certain amount of stored elastic energy is released. The fracture grows in an unstable way if the released energy is equal to or greater than the absorbed energy. The strain energy release rate $G$ is evaluated by the formula

$$
G=-\frac{1}{b}\left(\frac{\partial u_{i}}{\partial L_{f}}\right)
$$

which will be declined for cohesive and adhesive fractures in the forms

$$
G_{\mathrm{coh}_{X \%}}=-\left.\frac{1}{b}\left(\frac{\partial u}{\partial L_{f, \mathrm{coh}}}\right)\right|_{\frac{L_{f, \mathrm{coh}}}{t}=X \%}
$$

and

$$
G_{\mathrm{adh}_{X \%}}=-\left.\frac{1}{b}\left(\frac{\partial u}{\partial L_{f, \mathrm{adh}}}\right)\right|_{\frac{L_{f, \mathrm{adh}}}{l}=X \%}
$$

with $b$ the depth of the plate, $u_{i}$ the stored elastic energy, and $L_{f}$ the length of the fracture $\left[L_{f, \mathrm{coh}_{X \%}}\right.$ for cohesive fractures (Fig. $\underline{6 \mathrm{a}}$ ) and $L_{f, \text { adh }_{x \%}}$ for adhesive fractures (Fig. 6b)]. In the article, the computations will be performed for a depth of the plate $b$ equal to $1 \mathrm{~m}$. For cohesive fractures, the percentage $X \%$ is computed by considering the ratio of the cohesive fracture length compared to the plate thickness $t$. For adhesive fractures, the percentage $X \%$ is computed by considering the ratio of the adhesive fracture length compared to the length $l$ between a node and an antinode $l$. A value of $0 \%$ corresponds to no adhesive fracture, and $100 \%$ corresponds to a complete adhesive fracture. The strain energy release rate is compared with critical strain energy release rate to conclude on the propagation of fractures.

To study the initiation or propagation of ice fractures, it is necessary to have an approximate value of the cohesive tensile strength of the ice, of the adhesive shear strength of the ice with the substrate, and of the critical strain energy release rate. Although many experiments have been carried out to measure these values, there is a relatively wide range of ice strengths, and it is not easy to select a single value because ice strength depends on many factors: temperature [27-29], nature and roughness of the substrate [25], strain and strain rate [29,30], ice grain size [29], and flow speed [31]. Based on several articles $[28,32-35]$, the range of the ice tensile strength for fresh water is from [0.6-3] $\mathrm{MPa}$, and the range of the ice adhesive shear strength for fresh water is from [0.2-1] MPa. The ranges are very large because ice strength depends on many factors: temperature, nature and roughness of the substrate, strain and strain rate, ice grain size, and flow speed. From our experience, the values for ice obtained in a freezer tend to be on the upper limits of the range of variation. The critical strain energy release rate also depends on many factors, and it is difficult to find values of this parameter. The values used in this paper are extracted from [33], in which there is no distinction between cohesive and adhesive critical strain energy release rates, these two rates being of the same order of magnitude. The ranges of values of all parameters are given in Table 3 . They are of the same order of those selected by Villeneuve et al. in [24].

The computations presented in this paper have been run for a quarter-wavelength configuration thanks to the symmetric and antisymmetric boundary conditions. The fracture initiation is assumed to be located on antinodes, starting from the top surface of the ice layer for flexural modes. This assumption has been validated by the test results presented in $[16,24]$. For pure extensional modes, the fracture initiation is assumed to be located on the nodes where the stresses reach the maximum value. In practice, if the extensional mode is not pure, for modes combining flexion and extension, the fracture initiation occurs on antinodes as observed in [16]. The number of elements in the ice thickness is chosen equal to 10 in order to ensure the convergence of the shear stress values. Deformations and corresponding energies of deformations are evaluated through modal analyses.

Table 3 Strength and critical strain energy release rate

\begin{tabular}{lc}
\hline \hline Mechanical properties & Values \\
\hline Cohesive strength & {$[0.6-3] \mathrm{MPa}$} \\
Adhesive shear strength (ice/substrate) & {$[0.2-1] \mathrm{MPa}$} \\
Critical strain energy release rate, $G_{c}$ & {$[0.5-1] \mathrm{J} / \mathrm{m}^{2}$} \\
\hline \hline
\end{tabular}

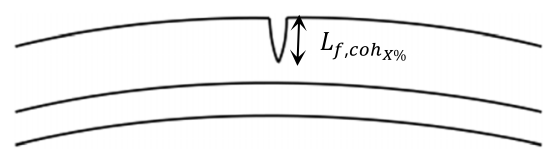

a)

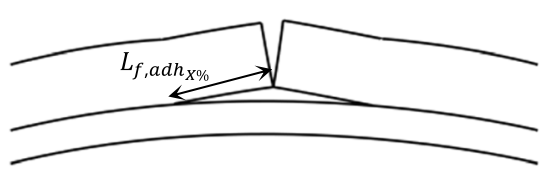

b)

Fig. 6 Definition of the fracture length for a) cohesive fractures and b) adhesive fractures. 


\section{Key Performance Indicators for Resonant De-Icing Systems}

\section{A. Objectives of Key Performance Indicators}

De-icing efficiency depends not only on the actuation system but also on the structure and the ice layer. Our objective is to define key performance indicators independent from the vibration amplitude that are representative of the performance of an architecture for a given resonance mode. A de-icing system is said to be efficient if it generates stress $\sigma$ and energy release rate $G$ that allows initiation and propagation of ice shedding fracture. The following sections will present key performance indicators which will enable one to evaluate the efficiency of resonant de-icing systems for both flexural and extensional modes, with respect to structural issues, energy, and different operational limits of the actuations systems (maximal mechanical stress, maximal voltage, power source limit). Key performance indicators are established here for the mechanism, which corresponds to the initiation of cohesive fractures caused by tensile stress, the propagation of cohesive fractures, and then potentially the propagation of adhesive fractures because it has been chosen to focus on this de-icing mechanism.

\section{B. Key Performance Indicators Image of Ability to Propagate Fractures}

The first set of proposed key performance indicators aims to measure the efficiency of the de-icing system for propagating cohesive or adhesive fractures.

The first proposed indicators show the ability of a structure to propagate fractures for a level of tensile stress within the ice: $\sigma$. As stress is proportional to vibratory amplitudes and the energy release rate is proportional to the square of vibratory amplitudes, to get indicators independent from the vibration amplitudes, the proposed key performance indicators are the ratio between the energy release rate and the square of tensile stress $\sigma$.

To study the propagation of cohesive fractures, a ratio between the cohesive energy release rate and the square of tensile stress $\sigma$ is defined:

$$
\mathrm{KPI}_{1_{\mathrm{coh}_{X \%}}}=\frac{G_{\mathrm{coh}_{X \%}}}{\sigma^{2}}
$$

To study the propagation of adhesive fractures after initiation of cohesive fractures caused by tensile stress, the key performance indicator is the ratio between the adhesive energy release rate and the square of tensile stress $\sigma$ :

$$
\mathrm{KPI}_{1_{\mathrm{adh}_{X \%}}}=\frac{G_{\mathrm{adh}_{X \%}}}{\sigma^{2}}
$$

These key performance indicators allow computing the values $G_{\mathrm{coh}_{X \%}}$ and $G_{\mathrm{adh}_{X \%}}$ for a given tensile stress $\sigma_{\text {tensile }}$ and, by comparison with a critical ratio computed with $G_{c}$, allow analyzing the ability to propagate fracture. These key performance indicators can also be indications of the ease to control the ice protection system. Indeed, if this key performance indicator is high enough so that adhesive deicing occurs just after initiation of cohesive fractures without change of the vibration magnitude used to initiate de-icing, control issues are easier to deal with. However, it does not represent the ultimate deicing performance; the use of vibration levels greater than those necessary for fractures initiation can lead to more significant fracture propagation. However, it can also lead to a frequency shift during the de-icing mechanism, and thus there is a need for frequency tracking.

\section{Energy Key Performance Indicators}

It is also interesting to study the tensile stress available to initiate cohesive fractures with respect to the mechanical energy. The elastic energy of deformation is related to the stresses into the support that must be minimized and to the energy consumed during a de-icing cycle. As the stored elastic energy of deformation $u$ is representative of the square of the vibration magnitude and because the stress is proportional to the vibratory amplitude, to get key performance indicators independent of the vibration amplitude and characteristic of the geometry, it is proposed to compute the ratio of tensile stress $\sigma$ where the fracture is likely to appear to the square root of the energy $u$ :

$$
\mathrm{KPI}_{2}=\frac{\sigma}{\sqrt{u}}
$$

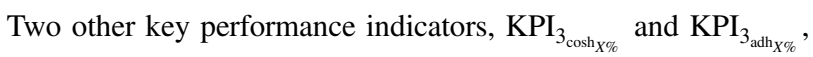
can be defined with respect to the stored elastic deformation energy. They correspond to the ratio of the energy release rates to the energy:

$$
\begin{aligned}
\mathrm{KPI}_{3_{\text {cosh }_{X \%}}}=\frac{G_{\mathrm{coh}_{X \%}}}{u} \\
\mathrm{KPI}_{3_{\mathrm{adh}_{X \%}}}=\frac{G_{\mathrm{adh}_{X \%}}}{u}
\end{aligned}
$$

$\mathrm{KPI}_{2}$ allows estimating the value of energy $u$ required to reach the value of tensile stress to initiate cohesive fractures, while $\mathrm{KPI}_{3_{\cosh _{X \%}}}$ and $\mathrm{KPI}_{3_{\text {adh }_{X \%}}}$ allow the computation of the energy $u$ required to reach the critical values $G_{c_{\text {coh }}}$ or $G_{c_{\text {adh }}}$ necessary to propagate cohesive and adhesive fractures, respectively. For the same reasons as for the previous key performance indicators, these key performance indicators are independent of the vibration amplitudes. The higher these ratios are, the more efficient the geometry for a given resonance mode is.

\section{Operational Limits of Actuation Systems Key Performance Indicators}

It may not be possible to reach the vibration amplitude or strain energy necessary to initiate or propagate the fractures. These limitations may be due to the inability of the actuation system to provide sufficient levels of excitation in power or effort. The next set of key performance indicators can be helpful for the designer to select a configuration compatible with the operational limits of the actuators or electronic power supply technologies.

\section{Key Performance Index Representative of Fracture Potential with Respect to Effort}

Two types of actuators can be considered to excite the structure at a given resonant frequency: piezoelectric actuators and electromagnetic actuators. The operating voltages of the piezoelectric actuators are limited to avoid depolarization and fracture of the ceramics. As voltage is proportional to the force capacity on the structure, the voltage limitation is also a force limitation. Voice coil type electromagnetic actuators are limited in supply current to avoid saturation of magnetic materials or overheating of the windings. The maximum current also limits the force on the structure because the torque and thus the force are proportional to the current. In these two cases, it is thus interesting to evaluate key performance indicators computed with respect to the maximal force of the actuator. We define

$$
\mathrm{KPI}_{4_{\mathrm{coh}_{X \%}}}=\frac{G_{\mathrm{coh}_{X \%}}}{F_{\text {max }}^{2}}
$$

and

$$
\mathrm{KPI}_{4_{\mathrm{adh}_{X \%}}}=\frac{G_{\mathrm{adh}_{X \%}}}{F_{\max }^{2}}
$$

For resonant systems characterized by quality factor $Q_{m}$ and that can be modeled by damped spring mass systems of stiffness $k$, the maximal force $F_{\max }$ needed to excite the systems can be written as

$$
F_{\text {max }}=\frac{k x_{\max }}{Q_{m}}
$$

and, as function of energy $u$, 


$$
F_{\max }=\frac{2 u}{x_{\max } Q_{m}}
$$

Thus, $\mathrm{KPI}_{4_{\mathrm{coh}_{X \%}}}$ and $\mathrm{KPI}_{4_{\text {adh }_{X \%}}}$ become

$$
\mathrm{KPI}_{4_{\mathrm{coh}_{X \%}}}=\frac{G_{\operatorname{coh}_{X \%}}}{\left(4 / Q_{m}^{2}\right)\left(u / x_{\max }\right)^{2}}=Q_{m}^{2} K_{4_{\mathrm{coh}_{X \%}}}
$$

where

$$
K_{4_{\mathrm{coh}_{X} \%}}=\frac{G_{\mathrm{coh}_{X \%}}}{4\left(u / x_{\max }\right)^{2}}
$$

and

$$
\mathrm{KPI}_{4_{\text {adh }_{X \%}}}=\frac{G_{\mathrm{adh}_{X \%}}}{\left(4 / Q_{m}^{2}\right)\left(u / x_{\max }\right)^{2}}=Q_{m}^{2} K_{4_{\text {adh }_{X \%}}}
$$

where

$$
K_{4_{\mathrm{adh}_{X \%}}}=\frac{G_{\mathrm{adh}_{X \%}}}{4\left(u / x_{\max }\right)^{2}}
$$

The coefficient $1 / Q_{m}^{2}$ is set out of the final expressions because the parameter $Q_{m}$ is difficult to estimate and variable with operating conditions. It is preferable to plot $K_{4_{\text {coh }_{X} \%}}$ and $K_{4_{\text {adh }_{X \%}}}$ independently of $Q_{m}$ and to select $Q_{m}$ later.

$\mathrm{KPI}_{4 \mathrm{coh}_{X \%}}$ and $\mathrm{KPI}_{4_{\text {adh }_{X \%}}}$ can be used to analyze the ability to propagate cohesive and adhesive fractures for a given force by comparing the computed values $G_{\mathrm{coh}_{X \%}}$ and $G_{\mathrm{adh}_{X \%}}$ with the critical values $G_{\text {ccoh }}$ or $G_{c_{\text {adh }}}$. Conversely, they can be used to compute the forces required to reach the critical values necessary to propagate cohesive and adhesive fractures.

\section{Key Performance Index Image of Fracture Potential with Respect to Power}

Electronics have power supply limitations. It is possible to compute a key performance indicator to point out the configurations maximizing the energy release rates while minimizing the power. Let us consider one resonant mode that can be modeled very simply by a low damped spring-mass system. The maximum mechanical power $P_{\text {mech }}$ at the resonance frequency is expressed by

$$
\begin{aligned}
P_{\text {mech }} & =\frac{1}{2} \cdot F_{\max } \cdot \dot{x}_{\max }=\frac{1}{2} \cdot F_{\max } \cdot \omega \cdot x_{\max }=\frac{1}{2} \cdot \frac{k x_{\max }}{Q_{m}} \omega \cdot x_{\max } \\
& =\frac{\omega u}{Q_{m}}
\end{aligned}
$$

with $x_{\max }$ and $\dot{x}_{\max }=\omega x_{\max }$ representing the maximal displacement and speed and $k$ representing the stiffness.

As the mechanical power is proportional to elastic energy $u$ and angular frequency $\omega$, it is therefore possible to propose two key performance indices $\mathrm{KPI}_{5_{\text {coh }_{X} \%}}$ and $\mathrm{KPI}_{5_{\text {adh }_{X \%}}}$ corresponding to the ratio of the energy release rate to the mechanical power brought to initiate fractures at the resonance,

$$
\mathrm{KPI}_{5_{\mathrm{coh}_{X \%}}}=\frac{G_{\mathrm{coh}_{X \%}}}{P_{\text {mech }}}=\frac{G_{\mathrm{coh}_{X \%}}}{\left(u \omega / Q_{m}\right)}=Q_{m} K_{5_{\mathrm{coh}_{X} \%}}
$$

where

$$
K_{5_{\mathrm{coh}_{X \%}}}=\frac{G_{\mathrm{coh}_{X \%}}}{u \omega}
$$

and

$$
\mathrm{KPI}_{5_{\text {adh }_{X \%}}}=\frac{G_{\mathrm{adh}_{X \%}}}{P_{\text {mech }}}=\frac{G_{\mathrm{adh}_{X \%}}}{\left(u \omega / Q_{m}\right)}=Q_{m} K_{5_{\text {adh }_{X \%}}}
$$

where

$$
K_{5_{\text {adh }_{X \%}}}=\frac{G_{\mathrm{adh}_{X \%}}}{u \omega}
$$

$\mathrm{KPI}_{5_{\mathrm{coh}_{X \%}}}$ and $\mathrm{KPI}_{5_{\text {adh } X \%}}$ can be used to compute either the ability to propagate cohesive or adhesive fractures for a given power or to estimate the amount of required power to de-ice.

\section{Computation of Key Performance Indicators}

\section{A. Assumptions for Computation of Key Performance Indicators}

The various key performance indicators proposed in the previous section are computed for a specific study case: a 1-mm-thick and 130-mm-long titanium plate covered by freezer ice. The ice is modeled as glaze ice defined as a homogenous material with a Young's modulus of $9.3 \mathrm{GPa}$, a Poisson's ratio of 0.33 , and a density of $920 \mathrm{~kg} / \mathrm{m}^{3}$ [16].

Key performance indicators are mainly computed and analyzed for pinned and clamped conditions. The free boundary conditions are considered for experimental verification because this configuration has the advantage to limit the uncertainties in the realization of the boundary conditions but are not analyzed more deeply because it is not a case with an industrial interest. The computations are performed for the first mode of flexion or extension of the plate and for different plate lengths $(40,80,160$, and $320 \mathrm{~mm})$ in order to study the evolution of the key performances indicators with the frequency. Finally, the computations are carried out for three ice layer thicknesses $(1,2$, and $3 \mathrm{~mm})$ to study the impact of this parameter.

All the combinations are evaluated according to a numerical full factorial design and allow analyzing the results with a mean effect analysis approach [37]. Results obtained with this approach are said to be given for a mean configuration.

\section{B. Key Performance Indicators Based on Ability to Propagate Fractures}

The first key performance indicators are computed to give information on fracture propagation with respect to structural issues. This section focuses on indicators $\mathrm{KPI}_{1_{\mathrm{coh}_{X \%}}}$ and $\mathrm{KPI}_{1_{\mathrm{adh}_{X \%}}}$ that give the ability to propagate cohesive and adhesive fractures for a given tensile stress. For cohesive fractures, we study the capacity of the fracture to propagate within the thickness of the ice. For adhesive fractures, as the study is performed for mechanism 1, it is assumed that these fractures occur after complete cohesive fractures, and the capacity of the fracture to delaminate the ice at the ice/substrate interface is analyzed.

First, key performance indicators $\mathrm{KPI}_{1_{\text {coh }_{X \%}}}$ and $\mathrm{KPI}_{1_{\text {adh } X \%}}$ are computed and analyzed for the test configuration (the titanium plate in free boundary conditions with a 1-, 2-, or 3-mm-thick ice layer) to show how to use them and also to validate them. We recall that the experiments are performed with piezoelectric actuators driven on the first resonance frequency mode and with a voltage amplitude that allows the initiation of cohesive fractures. Figures $\underline{7}$ and $\underline{8}$ show, respectively, the curves of $\mathrm{KPI}_{1_{\text {coh }_{X \%}}}$ and $\mathrm{KPI}_{1_{\text {adh }_{X \%}}}$ computed for an ice layer thickness of 1,2 , or $3 \mathrm{~mm}$. On the curves, the dotted line that corresponds to the limit $G_{c} / \sigma_{\text {tensile }}^{2}$ is also plotted. Based on our previous tests with glaze ice obtained in a freezer, $\sigma_{\text {tensile }}$ is chosen equal to $3 \mathrm{MPa}$, which is a conservative value. This value is used to compute the critical ratio $G_{c} / \sigma_{\text {tensile }}^{2}$ both for cohesive and adhesive fractures because, as only mechanism 1 is studied in this paper, it is assumed that adhesive fractures occur after cohesive fractures reach the interface. To take into account of the high uncertainties on the critical energy release rate $G_{c}$, the ratio $G_{c} / \sigma_{\text {tensile }}^{2}$ is computed for two extreme values of $G_{c}\left(0.5\right.$ and $\left.1 \mathrm{~J} / \mathrm{m}^{2}\right)$ to study the propagation of cohesive fractures or adhesive fractures.

For cohesive fractures, the curve of ratio $G / \sigma^{2}$ of the structure is increasing and then decreasing with the fracture lengths. When the curve of $G / \sigma^{2}$ crosses the limit $G_{c} / \sigma_{\text {tensile }}^{2}$, we can measure, at the 

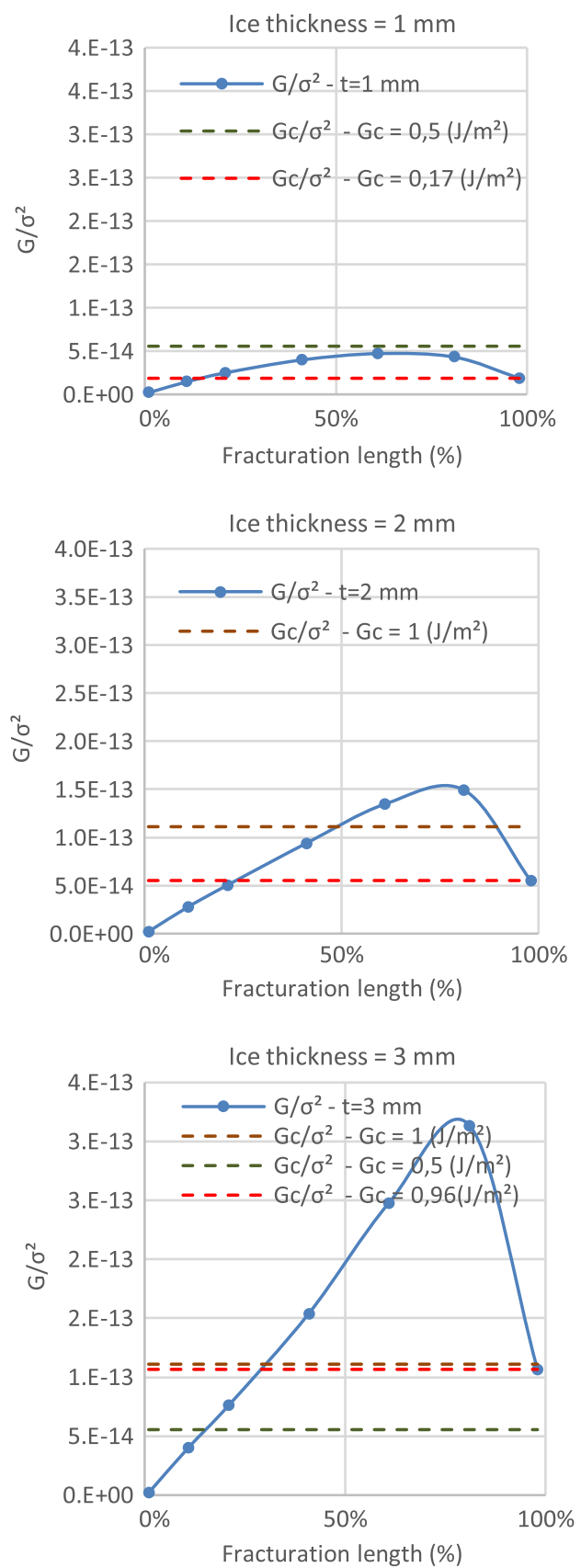

Fig. 7 Key performance indicator $\mathrm{KPI}_{1_{\cos _{X \%}}}$ computed for the test configuration.

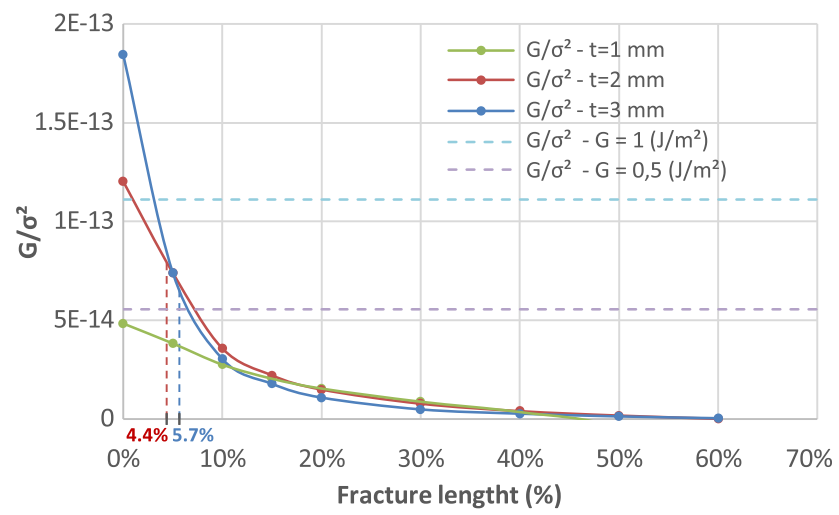

Fig. 8 Indicator $\mathrm{KPI}_{1_{\text {adh }_{X}}}$ computed for the test configuration. first intersection point, the critical length to get an unstable fracture that can propagate and, at the second intersection point, the maximum fracture length that be obtained.

For adhesive fractures, the ratio $G / \sigma^{2}$ of the structure is decreasing with the fracture lengths. The comparison with the critical ratio $G_{c} / \sigma_{\text {tensile }}^{2}$ is simple: if the ratio $G / \sigma^{2}$ is greater than the critical ratio $G_{c} / \sigma_{\text {tensile }}^{2}$, then fractures can propagate until the percentage of fracture length given by the intersection of the curve $G / \sigma^{2}$ with the limit $G_{c} / \sigma_{\text {tensile }}^{2}$.

The configuration with a 1-mm-thick ice layer is first analyzed. No adhesive fractures are observed. The length of the cohesive fracture has not been measured, but indicator $\mathrm{KPI}_{1_{\mathrm{coh}_{x}}}$ shows that, after initiation of the fractures, the propagation of the cohesive fractures in the ice layer is not possible. The curve of $\mathrm{KPI}_{1_{\text {coh }_{X \%}}}$ versus the fracture length is below the limit ratio $G_{c} / \sigma^{2}$ computed with $\sigma_{\text {tensile }}=3 \mathrm{MPa}$ and $G_{c}=0.5 \mathrm{~J} / \mathrm{m}^{2}$. To get a length of cohesive fracture equal to the thickness of the ice layer, the curve shows that a lower value of $G_{c}\left(G_{c}=0.17 \mathrm{~J} / \mathrm{m}^{2}\right)$ would be required. As the cohesive fracture has not propagated through the entire ice layer, the adhesive fracture cannot occur, which explains why it is not observed. For the tests with 2- and 3-mm-thick ice layers, a thin zone of delamination is observed and measured in Fig. 9: 4.4\% of delamination for the $2 \mathrm{~mm}$ configuration and $5.7 \%$ for the $3 \mathrm{~mm}$ configuration. The curves of $\mathrm{KPI}_{1_{\text {coh }_{X} \%}}$ show that the cohesive fractures very likely occur through the entire ice layer while the curves of $\mathrm{KPI}_{1_{a_{\text {adh }}{ }_{X \%}}}$ show the likelihood of obtaining only a few percent of delamination at the ice/substrate interface: between 1.5 (for $G_{c}=0.5 \mathrm{~J} / \mathrm{m}^{2}$ ) and $8 \%$ (for $G_{c}=1 \mathrm{~J} / \mathrm{m}^{2}$ ) of delamination for the $2 \mathrm{~mm}$ configuration and between 3 (for $G_{c}=0.5 \mathrm{~J} / \mathrm{m}^{2}$ ) and $7 \%$ (for $G_{c}=1 \mathrm{~J} / \mathrm{m}^{2}$ ) for the $3 \mathrm{~mm}$ configuration. These estimations are consistent with what is observed.

Second, key performance indicators $\mathrm{KPI}_{1_{\text {coh }_{X \%}}}$ and $\mathrm{KPI}_{1_{\mathrm{adh}_{X \%}}}$ are computed in the pinned and clamped conditions, for flexural and extensional modes and for a mean configuration of the plate (the KPIs under consideration are the means of the KPIs computed over the variation ranges of ice thickness and plate length). The objective is now to analyze the impact of the structure boundary conditions and of the type of mode on the de-icing efficiency.

Figure 10a gives the four curves of $\mathrm{KPI}_{1_{\text {coh }_{X \%}}}$ for pinned and clamped conditions and flexural and extensional modes. The dotted line corresponds to the limit $G_{c} / \sigma_{\text {tensile }}^{2}$ that is computed in this example for a $G_{c}$ value of $1 \mathrm{~J} / \mathrm{m}^{2}$ and a $\sigma_{\text {tensile }}$ value of $3 \mathrm{MPa}$, and that is thus equal to $1.1 \times 10^{-13}$. Figure $10 \mathrm{a}$ shows that the best configuration for cohesive fracture propagation is the clamped configuration in flexure but that the fracture will not propagate with the initial displacement of the antinodes that initiates the cohesive fractures. The fracture is stable until the fracture length reaches a critical value of $20 \%$. Thus, the vibration magnitude should be increased to reach that point, and only then will the fracture propagate over the entire ice thickness. Otherwise, the propagation does not occur or only over part of the ice thickness. The results for the pinned plate in flexure are not very far from the clamped plate in flexure. On the other hand, extensional modes do not propagate cohesive fractures effectively, regardless of the boundary conditions.

Figure $10 \mathrm{~b}$ displays the four curves of $\mathrm{KPI}_{1}$ for the pinned and clamped conditions for flexural and extensional modes, as well as the dotted line corresponding to the limit $G_{c} / \sigma_{\text {tensile }}^{2}$ computed for a value $G_{c}$ of $0.5 \mathrm{~J} / \mathrm{m}^{2}$ and a value $\sigma_{\text {tensile }}$ of $3 \mathrm{MPa}$. As for cohesive fracture, if the ratio $G / \sigma^{2}$ of the structure reaches this critical value, then the adhesive fracture can propagate. Figure $10 \mathrm{~b}$ shows that the best modes to be used are extensional modes, whatever the pinned or clamped conditions. With flexural modes, the best we can get is a delamination of only a few percent of the iced surface. This result is valid for the studied configuration. Of course, other configurations would give different results, and it is possible to get more delamination with flexural modes. In $[25,26]$, significant delamination was obtained for certain flexural modes (up to almost $100 \%$ ).

Finally, it is also interesting to analyze the change in the key performance indicators versus the ice layer thickness because this parameter, if it can be measured, can be taken into account in the 

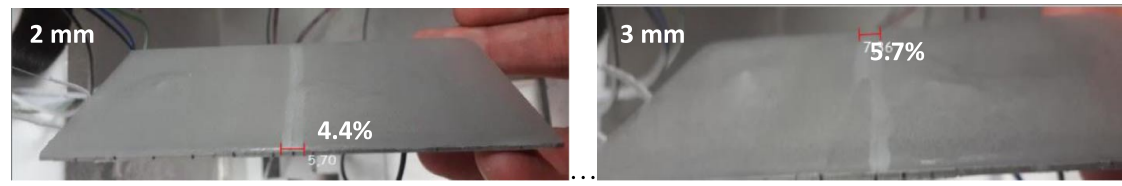

Fig. 9 Delamination results for tests with 2- and 3-mm-thick ice layers.
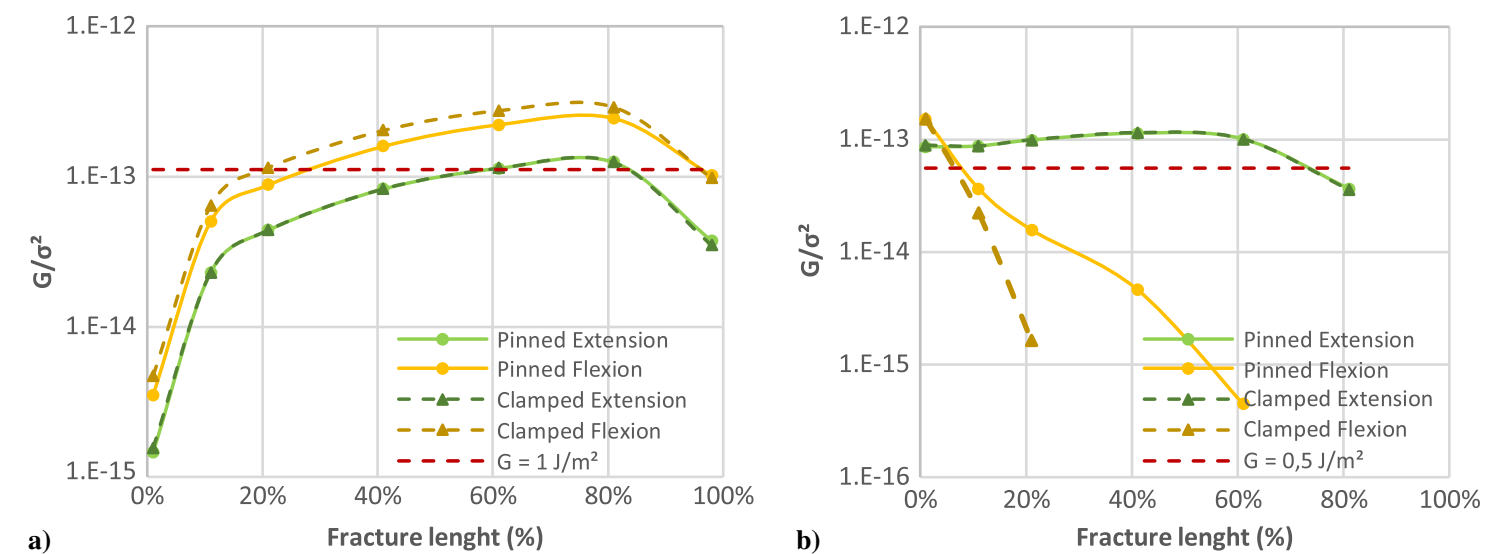

Fig. 10 Indicators: a) $\mathrm{KPI}_{1_{\text {coh }_{X}}}$ for studying cohesive fractures propagation and b) $\mathrm{KPI}_{1_{\mathrm{adh}_{X} \%}}$ for studying adhesive fractures propagation.

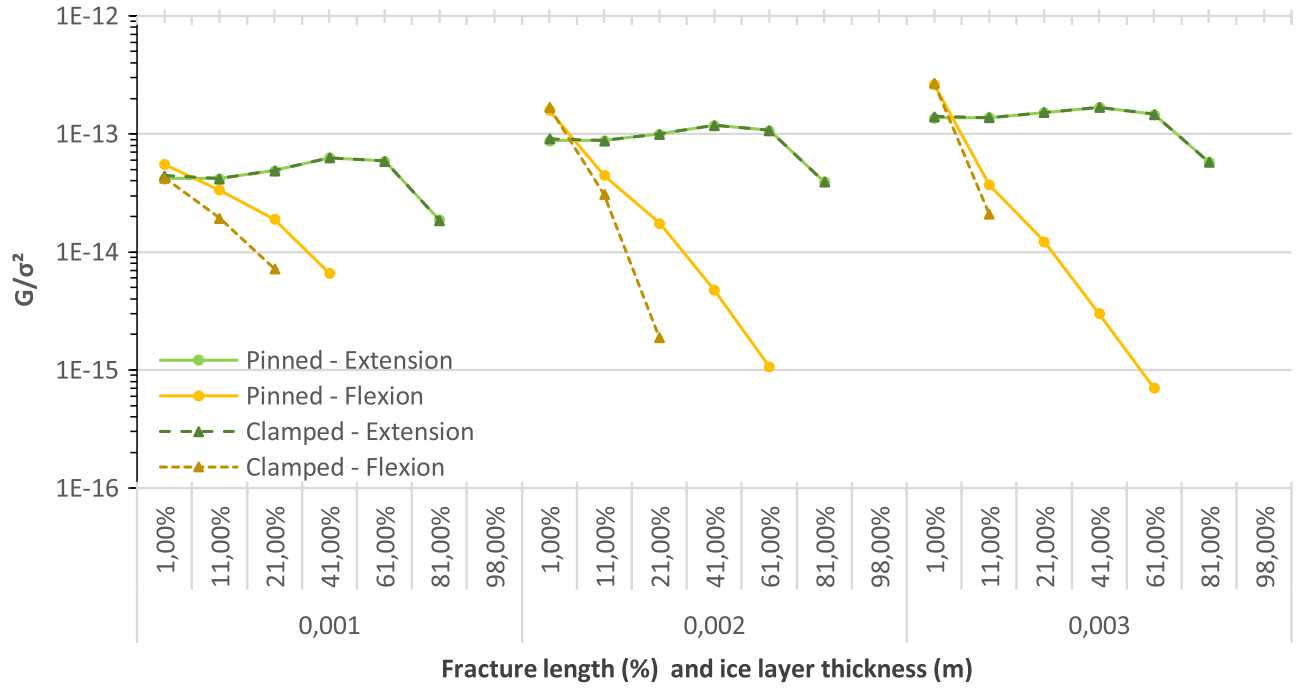

Fig. $11 \mathrm{KPI}_{1_{\text {adh }_{X \%}}}$ function of fracture length and ice layer thickness.

control of the resonant electromechanical de-icing system that will not run continuously. Figures $\underline{7}$ and $\underline{11}$ give $\mathrm{KPI}_{1_{\text {coh }_{X \%}}}$ and $\mathrm{KPI}_{1_{\text {adh }_{X \%}}}$ computed for a 130-mm-long plate and show that the largest ice layer thickness of the study $(3 \mathrm{~mm})$ favors the propagation of both cohesive and adhesive fractures whatever the boundary conditions.

This last figure (Fig. 11) shows that, for extensional modes with $G_{c}$ values between 1 and $0.5 \mathrm{~J} / \mathrm{m}^{2}$ (respectively, $G / \sigma^{2}=1.1 \times 10^{-13}$ and $G / \sigma^{2}=5.5 \times 10^{-14}$ ) and with a $3 \mathrm{~mm}$ ice layer, the maximal adhesive fracture length is around $80 \%$. This value is close to experimental results introduced previously in this paper (Fig. 5).

\section{Energy Key Performance Indicators}

Indicators $\mathrm{KPI}_{2}, \mathrm{KPI}_{3_{\text {coh }_{\chi} \sigma}}$, and $\mathrm{KPI}_{3_{\mathrm{adh}_{\chi} \sigma}}$ are now analyzed. Once again, computations are run for a mean configuration of the titanium plate.

Indicator $\mathrm{KPI}_{2}$ is computed to study the tensile stress available to initiate cohesive fractures with respect to the energy. KPI 2 in Fig. 12 is the mean of the KPIs computed over the variation ranges of ice thickness and plate length. First, Fig. 12 shows that the indicator increases with the frequency both for flexural and extensional modes. Second, a major difference can be observed between the curves for extensional and flexural modes. The larger value of $\mathrm{KPI}_{2}$ for flexural modes (Fig. 12a) shows the great interest in using flexural modes to initiate cohesive fractures. At last, Fig. 12 also displays the impact of the boundary conditions. For extensional modes (Fig. 12b), the impact of the boundary conditions is negligible, whereas for flexural modes, configurations with pinned boundary conditions will require less energy.

$\mathrm{KPI}_{3_{\text {coh }_{X \%}}}$ and $\mathrm{KPI}_{3_{\text {adh }_{X \%}}}$ which indicate the energy $u$ required to reach the critical values $G_{c_{\text {coh }}}$ or $G_{c_{\text {adh }}}$ necessary to propagate cohesive and adhesive fractures, respectively, are now analyzed. Figure 13a shows that cohesive fractures on the entire thickness of the ice are relatively easy to obtain because the final points of the curves correspond to nearly $100 \%$ of the fracture length. The figure also highlights that flexural modes for which the indicators are higher consume less energy to get these cohesive fractures. Concerning adhesive fractures, the results are not so hopeful. Figure 13b first 

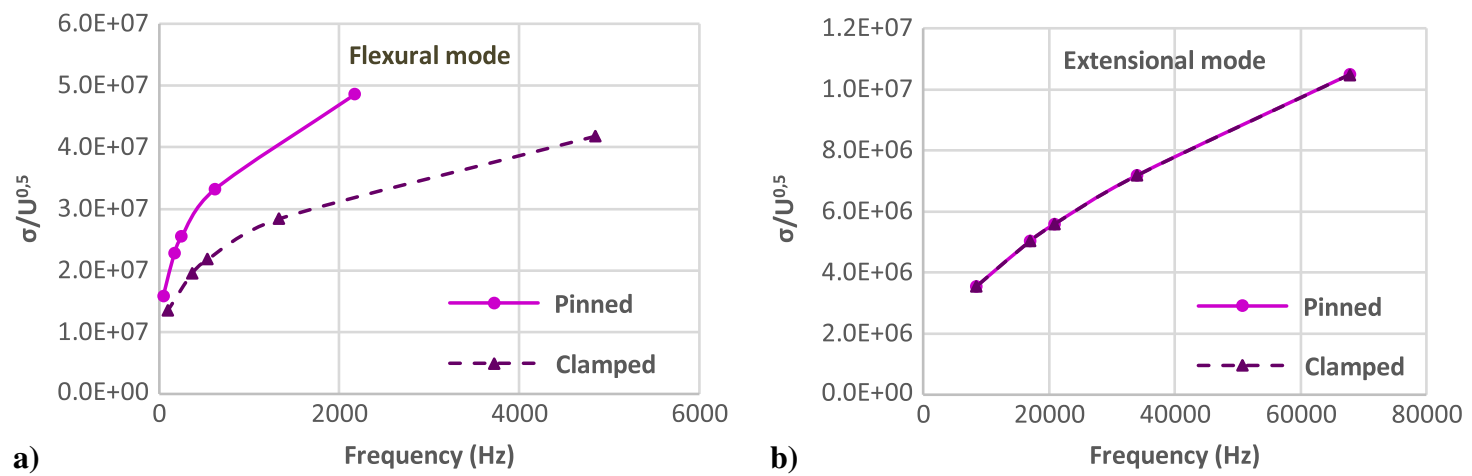

Fig.12 Indicator $\mathrm{KPI}_{2}$ versus frequency: a) for flexural and b) for extensional modes.
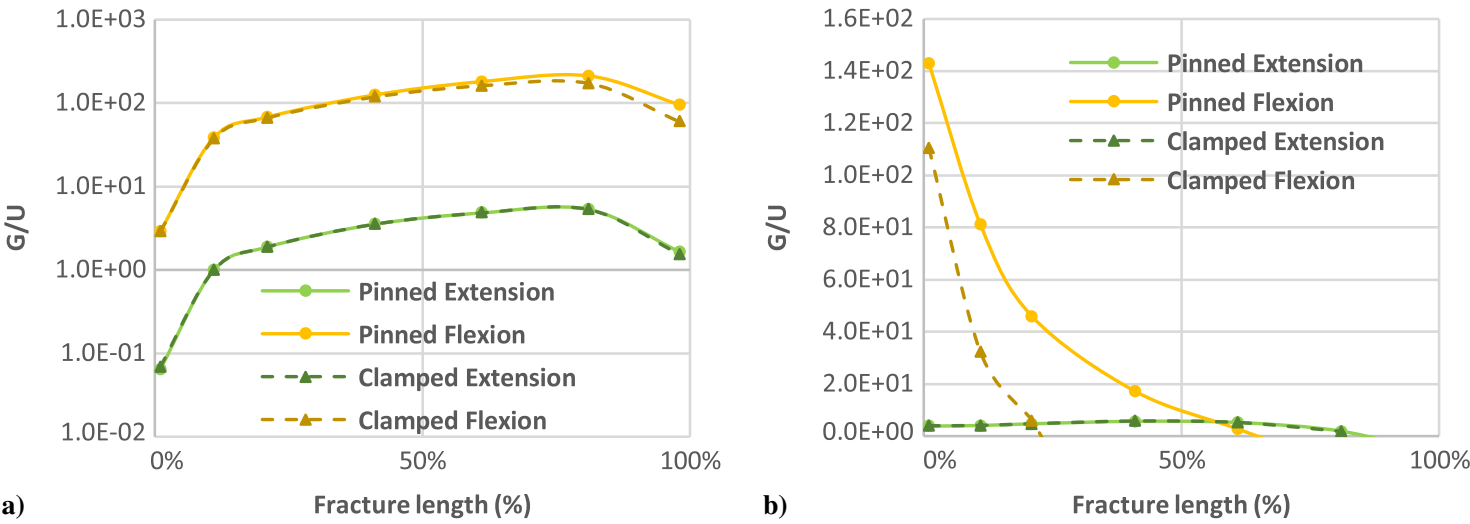

Fig. 13 Indicators: a) $\mathrm{KPI}_{\mathbf{3}_{\text {coh }_{X} \%}}$ versus fracture length and b) $\mathrm{KPI}_{3_{\text {adh }_{X} \%}}$ versus fracture length.

shows that, for flexural modes, the maximum fracture lengths are only $22 \%$ in the clamped conditions and $63 \%$ in the pinned conditions. Results are different for extensional modes; the de-icing efficiency is better because the fracture lengths can reach $85 \%$, but it will be at the cost of a much higher required energy because the values of the indicators are very low.

Then, the indicators $\mathrm{KPI}_{3_{\text {coh }_{X} \%}}$ and $\mathrm{KPI}_{3_{\text {adh }_{X} \%}}$ are computed over the variation ranges of fracture length and ice thickness and analyzed versus the frequency. The indicators $\mathrm{KPI}_{3_{\text {coh }_{X} \%}}$ and $\mathrm{KPI}_{3_{\text {adh }_{X \%}}}$ are also calculated versus the ice layer thickness and the plate half-length. For these last computations, indicators $\mathrm{KPI}_{3_{\text {coh }_{X} \%}}$ are computed for a cohesive length of $100 \%$, and indicators $\mathrm{KPI}_{3_{\text {adh }}{ }_{\mathrm{X}} \%}$ are computed for an adhesive length of $60 \%$. The analyses show that, for both computation conditions, the energy required for deicing is lower in the high frequency where indicators are higher and that flexural modes are less demanding in energy than extensional modes. The results also highlight, like for indicators $\mathrm{KPI}_{1}$, the benefit of large thicknesses and small plate lengths (while remaining within the studied ranges) to favor fracture propagation for a given energy.

\section{Key Performance Indicators for Actuations Systems Operational} Limits

The analysis of the ability to propagate fractures is of major importance, as well as energetic efficiency. However, it is also interesting to check other design criteria such as actuator force limitations or power limitations. The following set of figures has been generated while averaging the results for a set of cohesive and adhesive fracture lengths. In contrast to others indicators, $\mathrm{KPI}_{4}$ and $\mathrm{KPI}_{5}$ depend on the quality factor which is characteristics of resonant systems, highly variable and dependent on the type of modes [16]. To get a plot independent of this factor, we have decided to compute and a plot the indicators $K_{4_{\text {coh }_{X \%}}}$ and $K_{4_{\text {adh }_{X \%}}}$ as well as $K_{5_{\text {ch }_{X \%}}}$ and $K_{5_{\text {adh }_{X \%}}}$ for flexural and extensional modes versus frequency (Figs. 14 and 15). On these figures, indicators are computed for a mean configuration as in the previous sections, over the variation ranges of fracture length and ice thickness. For both indicators, curves for flexural and extensional modes are not plotted on the same figures because of the large difference in scales between the two charts. Indicators are much higher for flexural modes, showing that this type of mode is less demanding in power for the actuation systems, especially in low frequencies and for pinned conditions. For extensional modes, the difference between cohesive and adhesive fractures is small in the low frequency range (low for extensional modes but high for flexural modes because extensional modes exist at higher frequency than flexural modes), and at high frequency, the difference is smaller than for flexural modes.

To illustrate a practical application of these curves, an example of power estimation is given for an extensional mode at a frequency of $20 \mathrm{kHz}$. At this frequency, $\mathrm{KPI}_{5_{\text {adh }_{X \%}}}$ is equal to $1.5 \times 10^{-5}$. For extensional modes, a quality factor is assumed to be equal to 50 , corresponding to a mean value of experimental data given in [16]. For flexural modes, the quality factor is lower than that for extensional modes, and a value of 30 is closer to reality. Finally, for the computation, the highest value of the critical strain energy release rate of $1 \mathrm{~J} \cdot \mathrm{m}^{-2}$ is selected. With all this information and assumptions, the mechanical power required to de-ice $1 \mathrm{~m}^{2}$ is computed:

$$
P_{\text {mech }}=\frac{G_{\mathrm{adh}_{X \%}}}{Q_{m} K_{5_{\text {adh }_{X \%}}}}=\frac{1}{50 \times 1.5 \times 10^{-5}}=1.3 \mathrm{~kW}
$$

This value is computed for a mean value of the percentage of delamination. To get another idea of power consumption, the power is also computed for $80 \%$ delamination (which is nearly the maximum percentage that can be obtained with the pinned configuration and a 2 -mm-thick ice layer at a frequency of $66 \mathrm{kHz}$ ). For this case, the power is $1.8 \mathrm{~kW}$. These figures give examples of power consumption and show the potential reduction of power by a factor 10 , which could be obtained with resonant ice protection systems in comparison with electrothermal systems [38]. 

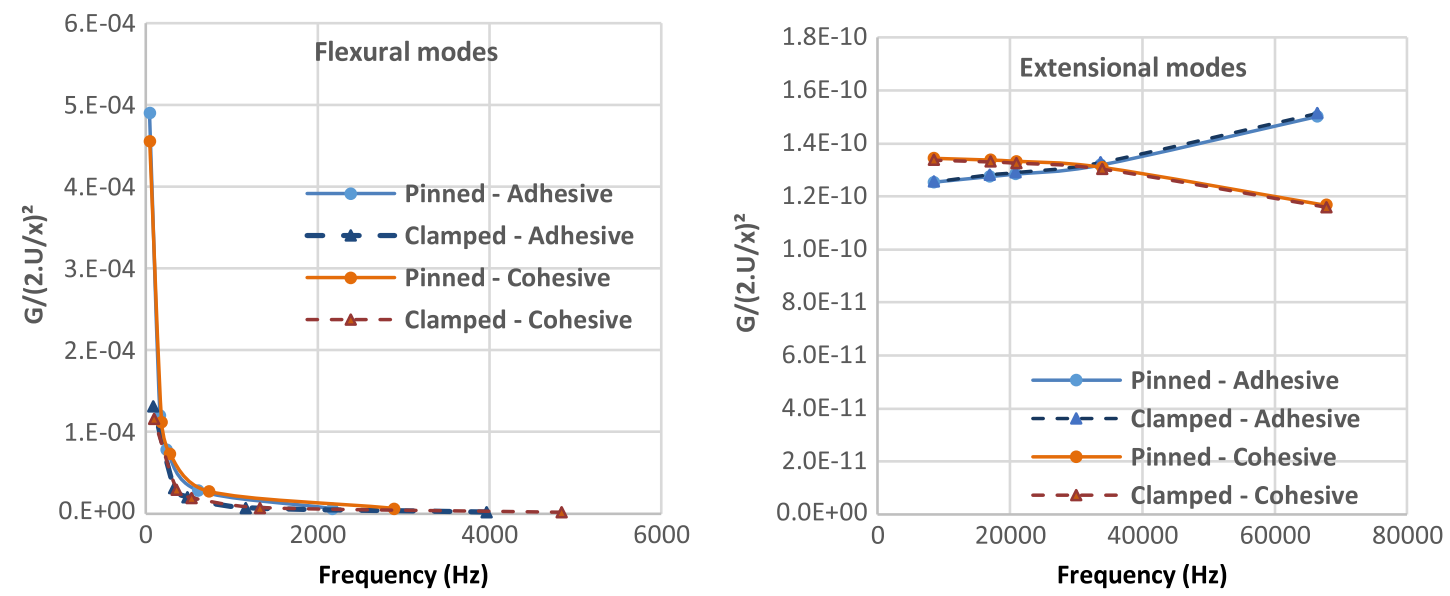

Fig. 14 Indicators $K_{4_{4} c o h}$ and $K_{4_{\text {adh }} x_{\%}}$ versus frequency for: a) flexural and b) extensional modes.
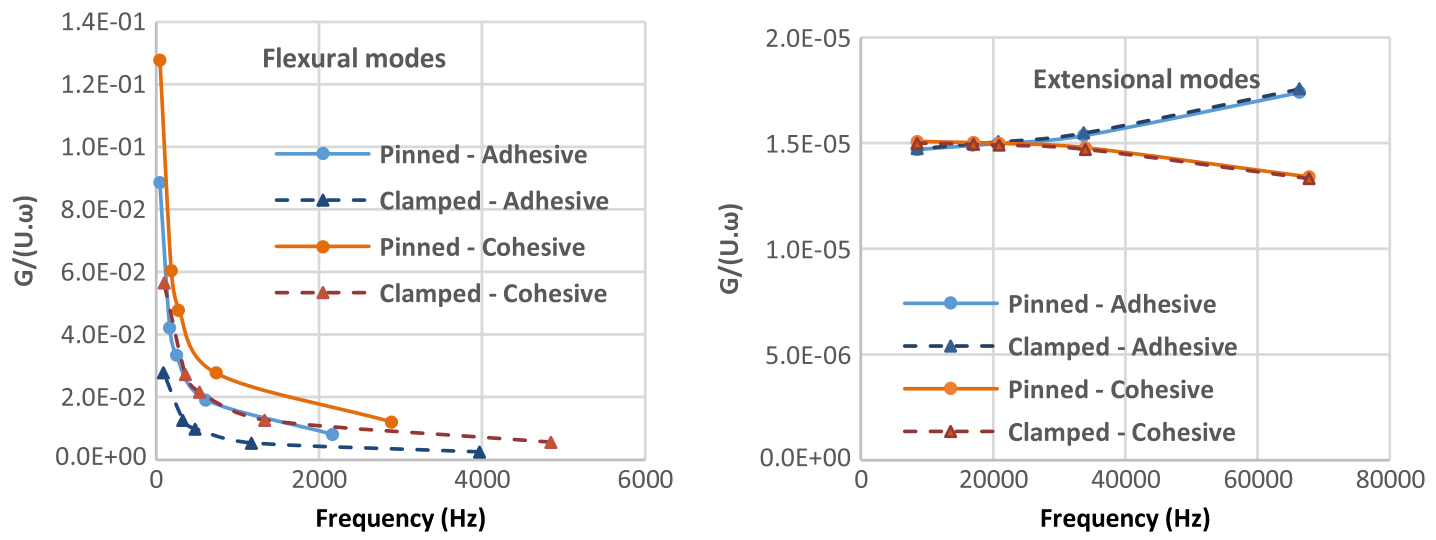

Fig. 15 Indicators $K_{5_{\text {coh }}}$ and $K_{5_{\text {adh }_{X \%}}}$ versus frequency for: a) flexural and b) extensional modes.

Please note that the power calculations only concern mechanical power. The apparent electrical power measured with piezoelectric deicing systems may be different. In the case of piezoelectric actuators, the electric current is composed of a motional current, which leads to active power, and a capacitive current, which leads to reactive power. To minimize the consumed electrical power, it is necessary to compensate the capacitive current, to provide only the motional current which corresponds to the mechanical power necessary for de-icing.

\section{Conclusions}

This paper focuses on the modeling of the de-icing capabilities of resonant ice protection systems. The work proposed key performance indicators to analyze the performance of such systems for fracture propagation, while checking the level of energy, force, and power required for removing freezer ice. The computation of the indicators requires three values: the ice cohesive strength, the adhesive shear strength at the ice/substrate interface, and the critical strain energy release rate. It is based on a de-icing mechanism divided into three steps: first, an initiation of the cohesive fractures by reaching the tensile stress limit at the top surface of the ice layer; second, a propagation of the cohesive fractures within the ice; and, third, a propagation of the adhesive fractures along the ice/substrate interface starting from the base of the cohesive fractures previously created.

In the paper, the key performance indicators have been computed for a specific case study. However, their analysis allows drawing some conclusions on the use of flexural and extensional modes and on the frequency range for different resonant ice protection systems to favor the initiation and propagation of fractures.

The initiation of cohesive fractures using flexural modes is less demanding in energy than using extensional modes and requires even lower energy for higher frequencies.
The propagation of cohesive fractures requires less energy with flexural modes, and provided that there is a minimum ice layer thickness, the fractures can spread over the entire thickness of the ice. Yet, there is a tradeoff on the frequency range to be used between power and energy: the high frequencies favor the required energy, while the low frequencies allow reducing the required power.

The propagation of the adhesive fractures is the major problem in this de-icing mechanism. This paper has proposed key performance indicators to estimate the capacity of a resonant de-icing system to propagate adhesive fractures. The computation results presented in this paper have shown that the propagation of such fractures on the entire interface is not obvious. The key performance indicators have highlighted that extensional modes allow getting larger surfaces of ice delamination than flexural modes but at the cost of much higher energy. By nature, extensional modes exist at higher frequencies than flexural modes, and the higher the frequency, the lower the required energy. However, the use of high frequencies (a few tens of kilohertz) constrains the actuation system and requires more power. Anyway, calculations based on the analyses proposed in this paper have shown a potential power reduction by a factor of 10 with resonant de-icing protection systems compared to electrothermal systems, which is very encouraging.

At the end of this study, which has proposed key performance indicators to help design resonant ice protection systems, many questions are still open. Is it possible to find architectures of resonant de-icing systems based on only one resonant mode? Are there configurations of the substrate that favor adhesive fracture propagation? Can such a system be efficient without being associated with an icephobic coating or electrothermal de-icing system? The computations presented in the framework of this paper are limited to pure flexural or extensional modes and uniform thicknesses of substrate and ice. Modes which combine flexure and extension and other 
geometrical configurations of ice and substrates exist, and they may be of interest for resonant ice protection systems and should be studied. Finally, the second mechanism with only delamination deserves interest, and studies similar to those developed in this paper could be carried out in future work.

\section{Acknowledgments}

This paper was partially supported by Sciences and Technologies for Aeronautics and Space-Midi-Pyrénées, France.

\section{References}

[1] Ramanathan, S., Varadan, V. V., and Varadan, V. K., "De-Icing of Helicopter Blades Using Piezoelectric Actuators," SPIE's 7th Annual International Symposium on Smart Structures and Materials, International Soc. for Optics and Photonics, Washington, D.C., 2000, pp. 281-292. https://doi.org/10.1117/12.388906

[2] Shi, Y., and Jia, Y., "Multimodal Shear Wave Deicing Using Fibre Piezoelectric Actuator on Composite for Aircraft Wings," IEEE/ASME Transactions on Mechatronics, Vol. 23, No. 5, 2018, pp. 2090-2098. https://doi.org/10.1109/TMECH.2018.2862433

[3] Venna, S. V., and Lin, Y. J., "In-Flight De-Icing Self-Actuating Wing Structures with Piezoelectric Actuators," Proceedings of American Society of Mechanical Engineers/International Mechanical Engineering Congress and Exposition, ASME, New York, 2002, pp. 237-245. https://doi.org/10.1115/IMECE2002-33992

[4] Venna, S. V., and Lin, Y. J., "Development of Self-Actuating In-Flight De-Icing Structures with Power Consumption Considerations," Proceedings of the American Society of Mechanical Engineers International Mechanical Engineering Congress and Exposition 2003, ASME, New York, 2003, pp. 45-53.

[5] Venna, S. V., and Lin, Y. J., "Mechatronic Development of SelfActuating In-Flight De-Icing Structures," IEEE/ASME Transactions on Mechatronics, Vol. 11, No. 5, 2006, pp. 585-592. https://doi.org/10.1109/TMECH.2006.882990

[6] Venna, S., Lin, Y. J., and Botura, G., "Piezoelectric Transducer Actuated Leading Edge De-Icing with Simultaneous Shear and Impulse Forces," Journal of Aircraft, Vol. 44, No. 2, 2007, pp. 509-515. https://doi.org/10.2514/1.23996

[7] Struggl, S., Korak, J., and Feyrer, C., "A Basic Approach for Wing Leading De-Icing by Smart Structures," SPIE Smart Structures and Materials + Nondestructive Evaluation and Health Monitoring, International Soc. for Optics and Photonics, Washington, D.C., , 2011, Paper 79815L

https://doi.org/10.1117/12.880470

[8] Palacios, J., Smith, E., and Rose, J., "Investigation of an Ultrasonic Ice Protection System for Helicopter Rotor Blades," Annual Forum Proceedings-American Helicopter Society, American Helicopter Soc., Vol. 64, No. 1, 2008, pp. 609-618.

[9] Palacios, J., Smith, E., Rose, J., and Royer, R., "Ultrasonic De-Icing of Wind-Tunnel Impact Icing," Journal of Aircraft, Vol. 48, No. 3, 2011, pp. 1020-1027. https://doi.org/10.2514/1.C031201

[10] Overmeyer, A., Palacios, J., and Smith, E., "Ultrasonic De-Icing Bondline Design and Rotor Ice Testing," AIAA Journal, Vol. 51, No. 12, 2013 , pp. $2965-2976$ https://doi.org/10.2514/1.J052601

[11] DiPlacido, N., Soltis, J., and Palacios, J., "Enhancement of Ultrasonic De-Icing via Tone Burst Excitation," Journal of Aircraft, Vol. 53, No. 6 , 2016, pp. 1821-1829. https://doi.org/10.2514/1.C033761

[12] Daniliuk, V., Xu, Y., Liu, R., He, T., and Wang, X., "Ultrasonic De-Icing of Wind Turbine Blades: Performance Comparison of Perspective Transducers," Renewable Energy, Vol. 145, Jan. 2020, pp. 20052018.

[13] Endres, M., Sommerwerk, H., Mendig, C., Sinapius, M., and Horst, P., "Experimental Study of Two Electro-Mechanical De-Icing Systems Applied on a Wing Section Tested in an Icing Wind Tunnel," CEAS Aeronautical Journal, Vol. 8, No. 3, 2017, pp. 429-439. https://doi.org/10.1007/s13272-017-0249-0

[14] Villeneuve, E., Harvey, D., Zimcik, D., Aubert, R., and Perron, J., "Piezoelectric De-Icing System for Rotorcraft," Journal of the American Helicopter Society, Vol. 60, No. 4, 2015, pp. 1-12. https://doi.org/10.4050/JAHS.60.042001

[15] Budinger, M., Pommier-Budinger, V., Napias, G., and Costa da Silva, A., "Ultrasonic Ice Protection Systems: Analytical and Numerical
Models for Architecture Tradeoff," Journal of Aircraft, Vol. 53, No. 3 , 2016, pp. 680-690.

https://doi.org/10.2514/1.C033625

[16] Pommier-Budinger, V., Budinger, M., Rouset, P., Dezitter, F., Huet, F., Wetterwald, M., and Bonaccurso, E., "Electromechanical Resonant Ice Protection Systems: Initiation of Fractures with Piezoelectric Actuators," AIAA Journal, Vol. 56, No. 11, 2018, pp. 4400-4411. https://doi.org/10.2514/1.J056662

[17] Bennani, L., "Two Dimensional Modelling of Electrothermal Ice Protection Systems," Ph.D. Dissertation, ONERA-The French Aerospace Lab, Toulouse, France, 2014.

[18] Marbœuf, A., Bennani, L., Budinger, M., and Pommier-Budinger, V., "Electromechanical Resonant Ice Protection Systems: Numerical Investigation Through a Phase-Field Mixed Adhesive/Brittle Fracture Model," Engineering Fracture Mechanics, Vol. 230, May 2020, Paper 106926. https://doi.org/10.1016/j.engfracmech.2020.106926

[19] Sommerwerk, H., and Horst, P., "Analysis of the Mechanical Behavior of Thin Ice Layers on Structures Including Radial Cracking and De-Icing," Engineering Fracture Mechanics, Vol. 182, Sept. 2017, pp. 400-424. https://doi.org/10.1007/s13272-017-0249-0

[20] Sommerwerk, H., Luplow, T., and Horst, P., "Numerical Simulation and Validation of Electro-Impulse De-Icing on a Leading Edge Structure," Theoretical and Applied Fracture Mechanics, Vol. 105, Feb. 2020, Paper 102392. https://doi.org/10.1016/j.tafmec.2019.102392

[21] Bailey, M. J., "Modeling and Experimental Testing of a Centrifugally Powered Pneumatic De-Icing System for Rotor Blades," Graduate Program Dissertation, Pennsylvania State Univ., State College, PA, 2014

[22] Drury, M. D., "Design and Testing of an Improved Centrifugally Powered Pneumatic De-Icing System for Helicopter Rotor Blades," Graduate Program Dissertation, Pennsylvania State Univ., State College, PA, 2016.

[23] Budinger, M., Pommier-Budinger, V., Bennani, L., Rouset, P., Bonaccurso, E., and Dezitter, F., "Electromechanical Resonant Ice Protection Systems: Analysis of Fracture Propagation Mechanisms," AIAA Journal, Vol. 56, No. 11, 2018, pp. 4412-4422. https://doi.org/10.2514/1.J056663

[24] Villeneuve, E., Volat, C., and Ghinet, S., "Numerical and Experimental Investigation of the Design of a Piezoelectric De-Icing System for Small Rotorcraft Part 3/3: Numerical Model and Experimental Validation of Vibration-Based De-Icing of a Flat Plate Structure," Aerospace, Vol. 7, No. 5,2020 , p. 54 https://doi.org/10.3390/aerospace7050049

[25] Villeneuve, E., Volat, C., and Ghinet, S., "Numerical and Experimental Investigation of the Design of a Piezoelectric De-Icing System for Small Rotorcraft Part 1/3: Development of a Flat Plate Numerical Model with Experimental Validation," Aerospace, Vol. 7, No. 5, 2020, p. 62 . https://doi.org/10.3390/aerospace7050062

[26] Villeneuve, E., Volat, C., and Ghinet, S., "Numerical and Experimental Investigation of the Design of a Piezoelectric De-Icing System for Small Rotorcraft Part 2/3: Investigation of Transient Vibration During Frequency Sweeps and Optimal Piezoelectric Actuator Excitation," Aerospace, Vol. 7, No. 5, 2020, p. 49. https://doi.org/10.3390/aerospace7050049

[27] Fortin, G., and Perron, J., "Ice Adhesion Models to Predict Shear Stress at Shedding," Journal of Adhesion Science and Technology, Vol. 26, Nos. 4-5, 2012, pp. 523-553. https://doi.org/10.1163/016942411X574835

[28] Makkonen, L., "Ice Adhesion-Theory, Measurements and Countermeasures," Journal of Adhesion Science and Technology, Vol. 26, Nos. 4-5, 2012, pp. 413-445. https://doi.org/10.1163/016942411X574583

[29] Petrovic, J. J., "Review Mechanical Properties of Ice and Snow," Journal of Materials Science, Vol. 38, No. 1, 2003, pp. 1-6. https://doi.org/10.1023/A:1021134128038

[30] Gold, L. W., "Engineering Properties of Fresh-Water Ice," Journal of Glaciology, Vol. 19, No. 81, 1977, pp. 197-212.

[31] Scavuzzo, R. J., and Chu, M. L., "Structural Properties of Impact Ices Accreted on Aircraft Structures," NASA 179580, 1987, pp. 41-42.

[32] Laforte, C., and Laforte, J. L., "De-Icing Strains and Stresses of Iced Substrates," Journal of Adhesion Science and Technology, Vol. 26, Nos. 4-5, 2012, pp. 603-620.

[33] Guerin, F., Laforte, C., Farinas, M. I., and Perron, J., "Analytical Model Based on Experimental Data of Centrifuge Ice Adhesion Tests with Different Substrates," Cold Regions Science and Technology, Vol. 121, 
Jan. 2016, pp. 93-99.

https://doi.org/10.1016/j.coldregions.2015.10.011

[34] Jellinek, H. H. G., "Adhesive Properties of Ice," Journal of Colloid Science, Vol. 14, No. 3, 1959, pp. 268-280.

https://doi.org/10.1016/0095-8522(59)90051-0

[35] Schulson, E. M., "The Structure and Mechanical Behavior of Ice," Journal of the Minerals, Metals and Materials Society, Vol. 51, No. 2, 1999, pp. 21-27.

https://doi.org/10.1007/s11837-999-0206-4

[36] Endres, M., Sommerwerk, H., Mendig, C., Sinapius, M., and Horst, P., "Experimental Study of Two Electro-Mechanical De-Icing Systems Applied on a Wing Section Tested in an Icing Wind Tunnel," CEAS
Aeronautical Journal, Vol. 8, No. 3, 2017, pp. 429-439.

https://doi.org/10.1016/j.engfracmech.2017.04.038

[37] Montgomery, D. C., Design and Analysis of Experiments, Wiley, New York, 2017, Chap. 5.

[38] Meier, O., and Schloz, D., "A Handbook Method for the Estimation of Power Requirements for Electrical De-Icing Systems," Deutscher Luftund Raumfahrt Kongress, German Aerospace Congress, Hamburg, Germany, 2010, https://www.fzt.haw-hamburg.de/pers/Scholz/ MOZART/MOZART_PRE_DLRK_10-08-31.pdf.

C. Wen Associate Editor 